\title{
Nasal Route of Administration
}

National Cancer Institute

\section{Source}

National Cancer Institute. Nasal Route of Administration. NCI Thesaurus. Code C38284.

Administration of a drug by the way of the nose. This often results in systemic action of the agent due to absorption through the nasal mucosa. The richly supplied vascular nature of the nasal mucosa coupled with its high drug permeation makes the nasal route of administration attractive for many drugs, including proteins and peptides. 